\title{
Use of multiple stress indices as a measure of heat tolerance in wheat accessions
}

\author{
Sachin Shehrawat ${ }^{1}$, Yogender Kumar ${ }^{1 *}$ and Jogendra Singh ${ }^{2}$ \\ ${ }^{1}$ Wheat and Barley Section, Department of Genetics and Plant Breeding, CCS Haryana Agricultural University, \\ Hisar-125004 (Haryana), India \\ ${ }^{2}$ ICAR-Indian Institute of Wheat and Barley Research, Karnal-132001, India
}

\section{Article history}

Received: 6 Oct., 2020

Revised : 1 Dec., 2020

Accepted: 19 Dec., 2020

\section{Citation}

Shehrawat S, Y Kumar and J Singh. 2020. Use of multiple stress indices as a measure of heat tolerance in wheat accessions. Journal of Cereal Research 12(3):297-308. http://doi. org/10.25174/2582-2675/2020/105658

\section{*Corresponding author}

Email: yogenderkgulia@gmail.com

(C) Society for Advancement of Wheat and Barley Research

\begin{abstract}
Wheat is a crop of global significance, grown in diversified environments. Heat stress affects a number of morpho-physiological traits in crops including wheat. A set of 40 wheat accessions along with four checks were screened for heat tolerance based on various stress indices. The present study was undertaken during rabi 201819 in randomized block design having three replications at CCS Haryana Agricultural University, Hisar under two dates of sowing i.e. $24^{\text {th }}$ November and $24^{\text {th }}$ December. Significant variance was observed among genotypes based on heat susceptibility index of all the traits except plant height and spike length. Based on heat susceptibility index and stress tolerance, the accessions DT 126, DT 46, DT 142, DT 102 and DT 124 were found to be most tolerant to heat stress, whereas on the basis of heat response index, heat tolerance index, mean productivity and geometric mean productivity, the promising accessions identified were DT 116, DT 101, DT 181, WH 1124, HD 3059 and DT190. The accessions identified as heat tolerant would form an important resource for the development of high yielding varieties under heat stress condition. Correlation coefficients based on HSI of different traits revealed significant positive association of grain yield per plant with biological yield per plant, harvest index, NDVI 1, tillers per plant and 1000 grain weight, denoting that these traits can be used effectively, for selection of heat tolerant genotypes. Grain yield was found to be positively correlated with the indices viz., HRI, HTI, MP and GMP while, negatively with HSI and TOL under stress condition. The stress indices used under study were recognized as paramount for identifying cultivars with high tolerance to heat stress.
\end{abstract}

Keywords: Wheat, heat stress, morpho-physiological, stress indices

\section{Introduction}

Wheat is one of the most important and widely cultivated crops in the world, belongs to the genus Triticum of the family Poaceae and tribe Triticeae. It is the second most important staple food next to rice, used mainly for human consumption and supports nearly 35\% of the world population (Mohammadi-joo et al., 2015) and provides about 20 per cent of the total food calories. It has been described as the 'King of cereals' because of the acreage it occupies, high productivity and the prominent position it holds in the international food grain trade. It is also known for its remarkable adoption to a wide range of environments and its role in the world economy.India has reported a record production of 107.18 million tonnes wheat from an area of 30.55 million hectare during the crop season 2019-20 with a productivity of 35.08 q/ha. In Haryana, 12.07 million tonnes wheat was produced on an area of 2.50 million hectare with average productivity of 48.29 q/ha (ICAR-IIWBR, 2020).

Abiotic stresses such as heat, cold, drought, salinity, and nutrient stress have a huge impact on world agriculture, 
and wheat is also no exception to this. Among abiotic stresses, heat stress is one of important abiotic stress which wheat faces today. The average global temperature is reported to be increasing at a rate of $0.18^{\circ} \mathrm{C}$ every decade (Hansen et al., 2012). Though, heat stress affects the metabolic pathways at every stage of life of wheat finally leading to yield reduction, the effect of high temperature is particularly severe during grain filling; these losses may be up to $40 \%$ under severe stress (Hays et al., 2007). Other effects of high temperatures includes decreased grain weight, early senescence, shriveled grains, reduced starch accumulation, altered starch-lipid composition in grains, lower seed germination and loss of vigour (Balla et al., 2012). To adapt new crop varieties to the future climate, we need to understand how crops respond to elevated temperatures and how tolerance to heat can be improved (Halford, 2009).

It is the need of the hour to counteract the detrimental effects of heat stress on global wheat production. Some of the adaptive measures which can mitigate terminal heat stress are surface cooling by irrigation (Lobell and Field, 2007), antioxidant defense (Caverzan et al., 2016), osmoprotectants (Kaushal et al., 2016), heat priming in early stages (Fan et al., 2018) and use of plant growth regulators (Sharma et al., 2019). Deryng et al. (2014) considered choice of cultivars and management of sowing dates as an adaptive measure under extreme heat stress conditions. The generation of improved pre-breeding material is indispensable for any breeding program (Ortiz et al., 2008). It requires the evaluation of genetic diversity for adaptation to future climatic conditions, and thereby the selection and induction of stress inducible genes of genetic resources for developing new varieties in the production systems (Chapman et al., 2012). Thus, there is an immediate need to explore genetic resources and develop such genotypes that can withstand terminal heat stress or can mature early without facing yield loss by escaping the stress conditions. Screening of genotypes under natural heat stress condition in various inconsistent environments is problematic. Susceptibility index proved to be a consistent parameter for selection of heat tolerant cultivars(Sharma et al., 2013).

Hence, the present investigation was undertaken to screen wheat accessions for their heat tolerance based on various stress indices.

\section{Materials and methods}

TThe present study was conducted at Research Area of Wheat and Barley Section of Department of Genetics \& Plant Breeding, CCS Haryana Agricultural University, Hisar which is located at latitude of $29^{\circ} 10^{\prime} \mathrm{N}$, longitude of $75^{\circ} 46^{\prime} \mathrm{E}$ and at an altitude of 215.2 meters above mean sea. The experimental material consisted of 40 wheat accessions along with four check varieties namely WH 711, WH 542, WH 1124 and HD 3059 grown in randomized block design (RBD) with 3 replications during rabi 201819. These wheat accessions were received from NBPGR, New Delhi for screening against stress tolerance.The experiment was planted at two dates of sowing i.e. normal sowing (24th November) and late sowing (24th December). Under both the conditions, recommended package of practices were followed. Each accession was planted in paired rows of $2.5 \mathrm{~m}$ length with inter-row and inter-plant distances of 20 and $10 \mathrm{~cm}$, respectively. Observations were recorded at specific stage on five randomly selected plants per accession per replication for 12 morphological traits viz.,days to heading, days to maturity, grain filling duration, plant height $(\mathrm{cm})$, peduncle length $(\mathrm{cm})$, tillers per plant, spike length $(\mathrm{cm})$, grains per spike, 1000 grain weight $(\mathrm{g})$, grain yield per plant $(\mathrm{g})$, biological yield per plant (g) and harvest index (\%) and 6 physiological traits viz., normalized difference vegetation index at anthesis (NDVI 1), normalized difference vegetation index at 15 days after anthesis (NDVI 2), canopy temperature at anthesis (CT 1), canopy temperature at 15 days after anthesis (CT 2), soil plant chlorophyll development at anthesis (SPAD 1) and soil plant chlorophyll development at 15 days after anthesis (SPAD 2).

Canopy temperature was recorded instantaneously with a hand held infrared thermometer (Model AG-42, Tele temp crop, Fullerton CA).The SPAD chlorophyll content was measured at anthesis (SPAD1) and 15 days after anthesis (SPAD2) by chlorophyll meter (Model No. Minolta SPAD502 Plus) which measure the greenness or the relative chlorophyll content of leaves.NDVI was measured at anthesis (NDVI1) and 15 days after anthesis (NDVI2) with the help of Green seeker hand held optical sensor unit (Model 505, NTech Industries, Inc., Ukiah, CA, USA).

Heat susceptibility index (HSI) of individual genotypes was calculated by the method suggested by Fischer and Maurer (1978). Heat response index (HRI) and stress tolerance 
Table 1. Weekly weather data during the crop season

\begin{tabular}{|c|c|c|c|c|c|c|}
\hline \multirow[t]{2}{*}{ Year } & \multirow[t]{2}{*}{ Week No. } & \multicolumn{3}{|c|}{ Temperature $\left({ }^{\circ} \mathrm{C}\right)$} & Relative humidity & \multirow[t]{2}{*}{ Rainfall (mm) } \\
\hline & & Max & Min & $\mathrm{M}$ & $\mathrm{E}$ & \\
\hline \multirow[t]{13}{*}{2018} & 40 & 34.4 & 20.0 & 90 & 40 & 0.0 \\
\hline & 41 & 32.5 & 17.9 & 86 & 43 & 0.0 \\
\hline & 42 & 33.4 & 16.5 & 73 & 30 & 0.0 \\
\hline & 43 & 31.4 & 14.4 & 84 & 36 & 0.0 \\
\hline & 44 & 31.0 & 15.4 & 92 & 44 & 0.0 \\
\hline & 45 & 27.4 & 10.1 & 90 & 41 & 0.0 \\
\hline & 46 & 27.5 & 12.7 & 91 & 53 & 0.0 \\
\hline & 47 & 27.4 & 10.9 & 87 & 44 & 0.0 \\
\hline & 48 & 27.2 & 9.4 & 93 & 46 & 0.0 \\
\hline & 49 & 24.9 & 7.5 & 96 & 45 & 0.0 \\
\hline & 50 & 21.0 & 7.7 & 91 & 57 & 0.0 \\
\hline & 51 & 20.7 & 2.0 & 93 & 50 & 0.0 \\
\hline & 52 & 19.8 & 1.9 & 94 & 49 & 0.0 \\
\hline \multirow[t]{18}{*}{2019} & 1 & 18.9 & 5.7 & 95 & 66 & 7.3 \\
\hline & 2 & 19.3 & 5.6 & 93 & 60 & 0.0 \\
\hline & 3 & 20.4 & 4.9 & 90 & 55 & 0.0 \\
\hline & 4 & 18.2 & 4.8 & 99 & 63 & 6.5 \\
\hline & 5 & 17.1 & 5.3 & 96 & 65 & 0.0 \\
\hline & 6 & 21.0 & 6.9 & 92 & 56 & 0.0 \\
\hline & 7 & 20.0 & 9.7 & 94 & 67 & 0.0 \\
\hline & 8 & 22.2 & 9.0 & 89 & 50 & 0.0 \\
\hline & 9 & 20.9 & 8.0 & 93 & 53 & 14.8 \\
\hline & 10 & 24.2 & 8.5 & 88 & 38 & 0.0 \\
\hline & 11 & 24.9 & 9.1 & 91 & 48 & 0.0 \\
\hline & 12 & 28.9 & 11.8 & 80 & 42 & 0.0 \\
\hline & 13 & 32.6 & 13.5 & 81 & 28 & 0.0 \\
\hline & 14 & 36.0 & 16.0 & 74 & 28 & 7.3 \\
\hline & 15 & 36.9 & 20.0 & 69 & 27 & 0.0 \\
\hline & 16 & 32.9 & 17.2 & 81 & 37 & 8.2 \\
\hline & 17 & 40.7 & 20.6 & 56 & 19 & 0.0 \\
\hline & 18 & 40.1 & 20.8 & 48 & 23 & 0.0 \\
\hline
\end{tabular}

(TOL)were computed using the formula given by Bidinger et al. (1987) and Hossain et al. (1990), respectively. Heat tolerance index (HTI)and geometric mean productivity (GMP) were worked out as per Fernandez (1993); and Mean productivity (MP)as described by Rosielle and Hamblin (1981).

The weather parameters during the crop season are presented in Table 1 . Weekly mean maximum temperature varied between 17.1 to $40.7^{\circ} \mathrm{C}$ whereas, the weekly mean minimum temperature was between 1.9 and $20.8{ }^{\circ} \mathrm{C}$. Morning $\mathrm{RH}$ varied from 48 to $99 \%$ while evening $\mathrm{RH}$ was highly variable with a range from 19 to $67 \%$. Total amount of rainfall received during the season at Hisar was $44.1 \mathrm{~mm}$.

\section{Results and Discussion}

The reduction in the performance of wheat accessions under terminal heat condition was expressed in terms of heat susceptibility index (HSI). The HSI of eighteen morpho-physiological traits were subjected to analysis of variance and mean sum of squares has been presented in Table 2. The results revealed hereby, the presence 
of significant variance among accessions for the HSI of all the traits except plant height and spike length. This implies that the magnitude of differences in accessions was enough to provide scope for selection with improved heat stress tolerance. The component of variance due to replications was found to be non significant for all the traits. These observations confirm with the findings of Bhusal et al. (2017).

The heat susceptibility index of different traits for forty wheat accessions and four check varieties have been depicted in Table 3 . The genotypes with high positive HSI values are susceptible to higher temperature and vice versa (Fisher and Maurer, 1978). The estimates of HSI or the important traits viz., grain yield per plant, biological yield per plant and harvest index can be utilized for selection of tolerant genotypes. The estimates of HSI for grain yield revealed that the accession DT 126 (0.05) followed by DT 142 (0.28), DT 102 (0.33), DT 46

Table 2. Mean sum of squares for HSI of different traits

\begin{tabular}{|c|c|c|c|c|c|c|c|c|c|c|}
\hline \multirow{2}{*}{$\begin{array}{l}\text { Source of } \\
\text { variation }\end{array}$} & \multirow[t]{2}{*}{ d. f. } & \multicolumn{9}{|c|}{ Mean sum of squares } \\
\hline & & $\mathrm{DH}$ & $\mathrm{DM}$ & GFD & NDVI 1 & NDVI 2 & CT 1 & CT 2 & SPAD 1 & SPAD 2 \\
\hline Replication & 2 & 0.002 & 0.0025 & 0.154 & 4.6065 & 0.3255 & 0.452 & 1.027 & 0.1225 & 0.065 \\
\hline Treatment & 43 & $0.028^{* *}$ & $0.045^{* *}$ & $0.389^{* *}$ & $9.225^{* *}$ & $2.754^{* *}$ & $1.949^{* *}$ & $12.857^{* *}$ & $1.949^{* *}$ & $2.819^{* *}$ \\
\hline Error & 86 & 0.007 & 0.007 & 0.083 & 1.337 & 0.713 & 0.326 & 1.664 & 0.428 & 0.881 \\
\hline
\end{tabular}

Continued.....

\begin{tabular}{|c|c|c|c|c|c|c|c|c|c|c|}
\hline \multirow{2}{*}{$\begin{array}{l}\text { Source of } \\
\text { variation }\end{array}$} & \multirow[t]{2}{*}{ d. $f$. } & \multicolumn{9}{|c|}{ Mean sum of squares } \\
\hline & & $\mathrm{PH}$ & PL & SL & TIL & GPS & TGW & $\mathrm{BY}$ & GY & $\mathrm{HI}$ \\
\hline Replication & 2 & 1.90 & 0.1375 & 0.653 & 0.464 & 0.605 & 0.279 & 0.338 & 0.142 & 1.623 \\
\hline Treatment & 43 & 12.302 & $1.235^{*}$ & 0.847 & $2.925^{* *}$ & $2.841^{* *}$ & $4.61^{* *}$ & $0.918^{* *}$ & $0.426^{* *}$ & $6.227^{* * *}$ \\
\hline Error & 86 & 8.365 & 0.762 & 0.667 & 0.336 & 0.32 & 0.399 & 0.193 & 0.094 & 1.241 \\
\hline
\end{tabular}

**, * Significant at 1 and $5 \%$ level, respectively

(DH: Days to heading, DM: Days to maturity, GFD: Grain filling duration, NDVI 1: Normalized difference vegetation index at anthesis, NDVI 2: Normalized difference vegetation index at 15 days after anthesis, CT 1: Canopy temperature at anthesis, CT 2: Canopy temperature at 15 days after anthesis, SPAD 1: Soil plant chlorophyll development at anthesis, SPAD 2: Soil plant chlorophyll development at 15 days after anthesis, PH: Plant height, PL: Peduncle length, SL: Spike length, TIL: Tiller per plant, GPS: Grains per spike, TGW: 1000-grain weight, BY: Biological yield per plant, GY: Grain yield per plant, HI: Harvest index)

(0.37) and DT 124 (0.46), exhibited minimum values of HSI, therefore, these accessions possessed low heat susceptibility and high yield stability under heat stress condition. In contrast, DT 104 (1.71) recorded with maximum value of HSI for grain yield and was identified as highly susceptible to heat. For the trait biological yield per plant, minimum HSI was shown by DT $124(-0.21)$ followed by DT 142 (-0.02), WH 711 (-0.06), DT 102 (0.04) and DT 46(0.13). Similarly, for harvest index HSI was minimum for accession DT 127 (-2.90) followed by DT 126 (-2.66). All these accessions showed their superiority for tolerance to high temperature than other genotypes. HSI was also used by Islam et al. (2017) and Sareen et al. (2020) to classify genotypes into different categories i.e. heattolerant, moderatelyheattolerantandheatsusceptible. Correlation coefficients were worked out based on HSI of different traits, to estimate the degree of association among various characters for heat tolerance (Table 4).Grain yield per plant exhibited significant positive association with biological yield per plant, harvest index, NDVI 1, tillers per plant and 1000 grain weight, showing the importance and effectiveness of these traits for detection and screening of high yielding and thermotolerant genotypes under normal and stress conditions. Significant positive correlations were also observed for days to maturity with days to heading and grain filling duration; NDVI 1 with CT 1, CT 2, grains per spike and biological yield; NDVI 2 with SPAD 2; CT 1 with grains per spike; CT 2 with plant height; spike length with biological yield; tillers per plant with 1000 grain weight and biological yield; and 1000 grain weight with grains per spike and biological yield. Similarly, signifi- 


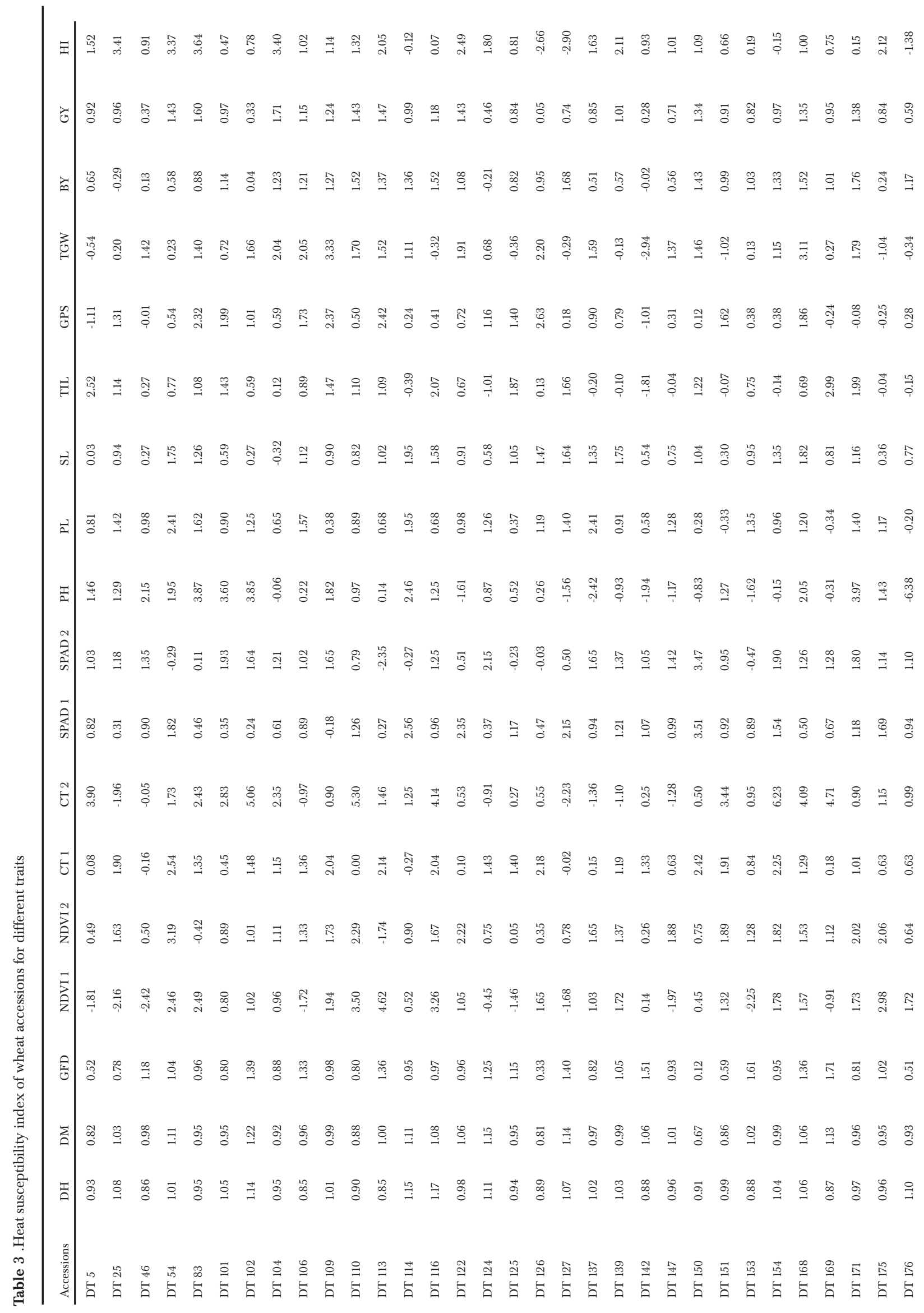




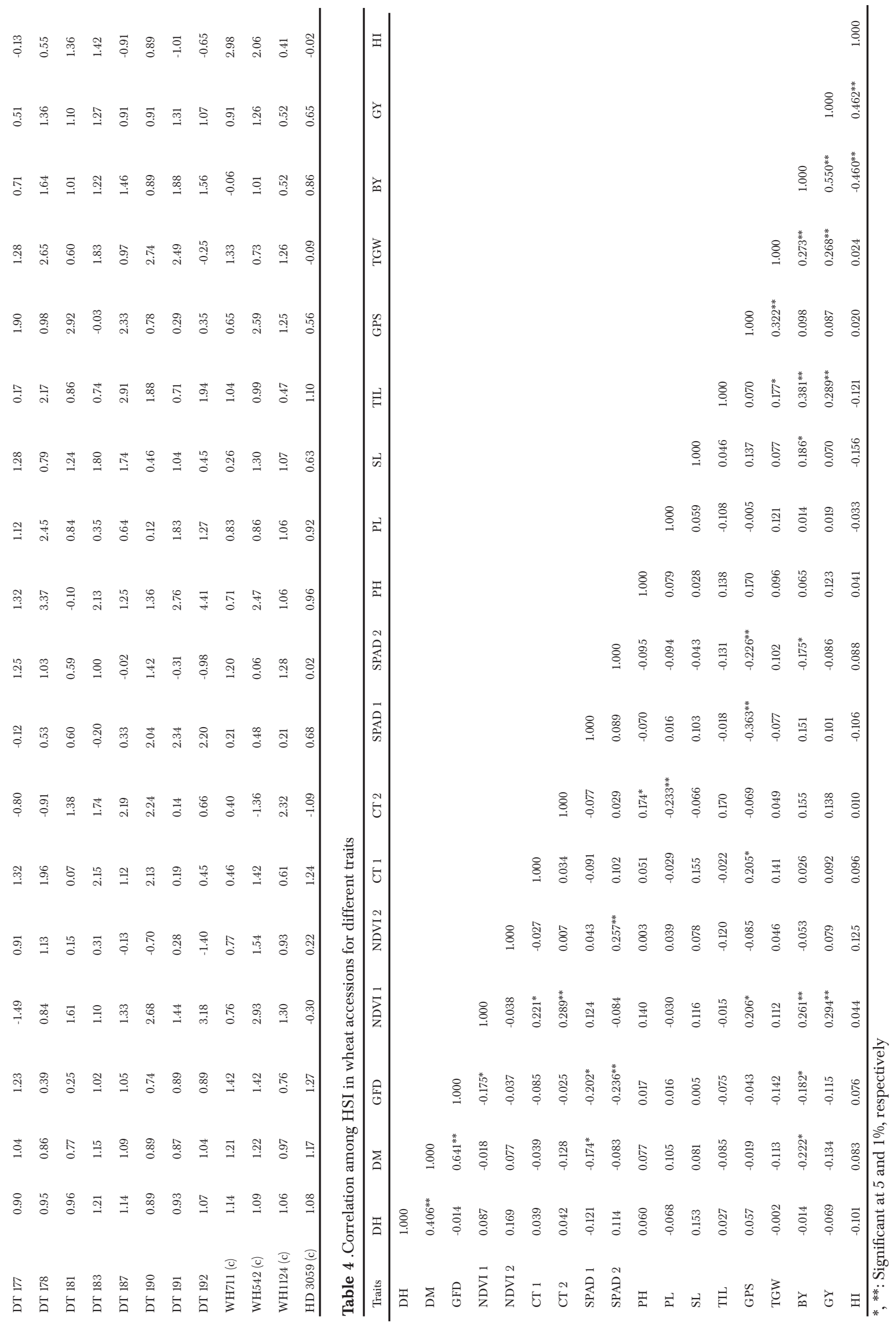


Table 5. Stress indices for grain yield in wheat accessions

\begin{tabular}{|c|c|c|c|c|c|c|}
\hline Accessions & Accession No. & HRI & HTI & TOL & MP & GMP \\
\hline DT 5 & IC 335583 & -0.71 & 0.68 & 3.73 & 10.63 & 10.46 \\
\hline DT 25 & IC 335966 & -1.93 & 0.54 & 3.53 & 9.53 & 9.35 \\
\hline DT 46 & EC 609336 & 0.66 & 0.23 & 0.90 & 6.12 & 6.06 \\
\hline DT 54 & EC 276983 & 0.63 & 0.33 & 4.70 & 7.68 & 7.30 \\
\hline DT 83 & IC 296756 & -1.20 & 0.40 & 6.00 & 8.57 & 8.02 \\
\hline DT 101 & IC 543401 & 0.64 & 1.13 & 5.13 & 13.73 & 13.49 \\
\hline DT 102 & EC 277323 & 0.39 & 0.92 & 1.37 & 12.22 & 12.19 \\
\hline DT 104 & EC 276920 & 0.32 & 0.68 & 8.67 & 11.30 & 10.42 \\
\hline DT 106 & IC 534137 & -0.63 & 0.71 & 5.00 & 11.00 & 10.70 \\
\hline DT 109 & IC 402058 & -0.66 & 0.75 & 5.77 & 11.42 & 11.04 \\
\hline DT 110 & IC 276717 & -0.14 & 0.53 & 5.87 & 9.70 & 9.24 \\
\hline DT 113 & IC 542124 & 0.73 & 0.36 & 5.03 & 7.98 & 7.55 \\
\hline DT 114 & EC 313735 & 1.20 & 0.27 & 2.77 & 6.72 & 6.53 \\
\hline DT 116 & EC 519498 & 0.79 & 1.22 & 6.93 & 14.50 & 14.05 \\
\hline DT 122 & EC 577722 & 0.88 & 0.30 & 4.40 & 7.30 & 6.95 \\
\hline DT 124 & IC 47337 & -0.67 & 0.64 & 1.63 & 10.18 & 10.15 \\
\hline DT 125 & EC 609337 & -0.22 & 0.95 & 4.00 & 12.57 & 12.40 \\
\hline DT 126 & EC 445157 & -1.29 & 0.43 & 0.30 & 8.35 & 8.31 \\
\hline DT 127 & EC 609574 & 0.23 & 0.59 & 2.83 & 9.88 & 9.76 \\
\hline DT 137 & IC 35143 & 0.60 & 0.40 & 2.80 & 8.23 & 8.07 \\
\hline DT 139 & IC 335968 & 0.42 & 0.92 & 4.87 & 12.40 & 12.15 \\
\hline DT 142 & IC 111844 & -0.41 & 0.73 & 1.17 & 10.92 & 10.88 \\
\hline DT 147 & IC 445528 & 0.17 & 0.78 & 2.93 & 11.30 & 11.20 \\
\hline DT 150 & IC 535772 & 0.04 & 0.68 & 6.07 & 10.93 & 10.50 \\
\hline DT 151 & IC 535518 & 0.23 & 0.99 & 4.60 & 12.87 & 12.63 \\
\hline DT 153 & EC 276814 & -0.33 & 0.32 & 2.37 & 7.25 & 7.12 \\
\hline DT 154 & IC 543364 & 0.09 & 0.74 & 4.17 & 11.15 & 10.95 \\
\hline DT 168 & EC 276864 & 0.28 & 0.53 & 5.53 & 9.67 & 9.22 \\
\hline DT 169 & IC 547701 & -0.13 & 0.89 & 4.43 & 12.15 & 11.94 \\
\hline DT 171 & EC 295392 & -0.30 & 0.46 & 5.17 & 8.98 & 8.60 \\
\hline DT 175 & EC 478016 & -0.19 & 0.71 & 3.40 & 10.80 & 10.67 \\
\hline DT 176 & EC 299085 & -0.21 & 0.75 & 2.40 & 11.03 & 10.96 \\
\hline DT 177 & EC 573837 & 0.36 & 1.00 & 2.33 & 12.73 & 12.68 \\
\hline DT 178 & IC 128664 & -0.04 & 0.61 & 5.87 & 10.37 & 9.94 \\
\hline DT 181 & EC 577619 & 0.75 & 1.01 & 5.70 & 13.12 & 12.80 \\
\hline DT 183 & IC 535848 & -0.32 & 0.59 & 5.30 & 10.12 & 9.74 \\
\hline DT 187 & IC 445522 & 0.30 & 0.88 & 4.30 & 12.15 & 11.93 \\
\hline DT 190 & IC 335932 & 0.18 & 1.06 & 4.67 & 13.30 & 13.08 \\
\hline DT 191 & EC 519501 & -0.87 & 0.44 & 4.73 & 8.73 & 8.40 \\
\hline DT 192 & EC 13263 & -1.29 & 0.60 & 4.20 & 10.07 & 9.84 \\
\hline WH711 (c) & - & -0.76 & 0.74 & 3.93 & 11.13 & 10.94 \\
\hline WH542 (c) & - & 0.34 & 0.59 & 5.30 & 10.12 & 9.74 \\
\hline WH1124 (c) & - & 1.47 & 1.48 & 2.87 & 15.53 & 15.47 \\
\hline HD3059 (c) & - & 0.64 & 1.20 & 3.40 & 14.07 & 13.92 \\
\hline
\end{tabular}

(HRI: Heat response index, HTI:Heat tolerance index,TOL: Stress tolerance, MP: Mean productivity and GMP: Geometric mean productivity) 
cant negative correlation was recorded for days to maturity with SPAD 1 and biological yield; grain filling duration with NDVI 1, SPAD 1, SPAD 2 and biological yield; CT 2 with peduncle length; number of grains per spike with SPAD 1 and SPAD 2; and biological yield with SPAD 2 and harvest index. These results corroborates with the findings of Mason et al. (2010), Paliwal et al. (2012), Sharma et al. (2016) and Bhusal et al. (2017). In order to further validate the results obtained by analysis of HSI, five other stress indices viz., heat response index (HRI), heat tolerance index (HTI), stress tolerance (TOL), mean productivity (MP) and geometric mean productivity (GMP) were worked out based on grain yield under normal and stress conditions. The estimates of stress indices for grain yield in wheat accessions have been showed in Table 4, while Fig. 1 depicts a radar graph representing the most promising accessions based on different stress indices i.e. WH 1124 based on HRI, HTI, MP and GMP; and DT 126 based on TOL.The estimate of stress tolerance (TOL) was observed minimum for DT 126 (0.30) followed by DT 46 (0.90), DT 142 (1.17), DT 102 (1.37) and DT 124 (1.63), exhibiting lower yield reduction under heat stress whereas, higher yield reduction was recorded in DT 104 (8.67) that showed high value of TOL. Similar results were also observed by Hassan et al. (2016) and Mohammadi et al. (2011). Heat response index is more useful criteria of selection as it categories the genotype based on the mechanism of heat tolerance i.e. escape, resistance or tolerance (Munjal and Dhanda, 2016). The promising accessions identified on the basis of high heat response index were WH 1124 (1.47), DT 114 (1.20), DT 122 (0.88), DT 116 (0.79), DT $181(0.75)$ and DT 113(0.73). Heat response index was also used earlier by Suresh et al. (2018) to evaluate heat tolerance in Triticum aestivum, Triticum durum and triticale cultivars. The accession WH 1124 followed by DT 116, HD 3059, DT 101, DT 190 and DT 181 were found superior over the others in terms of yield, according to the estimates of heat tolerance index (HTI), mean productivity (MP) and geometric mean productivity (GMP) indices. Theseaccessions showed considerable potential to improve heat tolerance in wheat breeding programs, based on different stress tolerance indices. Various stress indices like HTI, MP and GMP have also been used by Puri et al. (2015), Mohammadi and Abdulahi (2017); and
Meena et al. (2019) for evaluation and screening of heat tolerant genotypes.Based on the stress indices, viz., HSI, HRI, HTI, TOL, MP and GMP, the late sown check variety WH 1124 was found superior to other check varieties used in the study, therefore WH 1124 can serve as standard mean for these stress indices. The individual ranks of accessions for different stress indices were used to work out average and overall rank (Table 6). The accession DT 177, followed by DT 102, DT 101, DT 190 and DT 151 were found most tolerant to heat stress based on the overall ranks. The overall rank of accessions, exhibited a negative correlation of -0.863 with grain yield under stress condition, signifying that better ranked accessions had greater yield under stress condition. Further, correlation coefficient analysis among different stress indices and with grain yield was carried out and estimates are illustrated in Table 7. Grain yield under stress condition was found to be positively correlated with the indices viz.,HRI, HTI,MP and GMP whereas, it was negatively correlated with HSI and TOL, signifying that higher estimates of HRI, HTI, MP and GMP, and lower of HSI and TOL correspond to heat tolerance.The stress indices HTI and GMP exhibited maximum positive correlation with grain yield under stress condition; therefore, they can be regarded as the best selection criteria for heat stress tolerance.Under normal sown,grain yield recorded significant positive correlation with all the stress indices except HRI. Likewise, among the stress indices, significant positive association were observed for HSI with TOL; HTI with HRI, MP and GMP; and MP with TOL and GMP. The results also revealed significant negative association of HSI with HTI and GMP. Similar interrelationship among these stress indices reflected in the findings of Mohammadi et al.(2011),Suresh et al. (2018) and Meena et al. (2019). Khan et al. (2014) and Puri et al. (2015) also recorded significant positive association of MP, GMP and HTI with grain yield under normal and stress conditions. Hence, the stress indices used under study were recognized as paramount for identifying cultivars with high tolerance to heat stress.

\section{Acknowledgment}

The authors expresses sincere gratitude to Head, Wheat and Barley Section (GPB), CCS HAU, Hisar-125004 for providing research facilities and NBPGR, New Delhi for sharing the experimental material. 


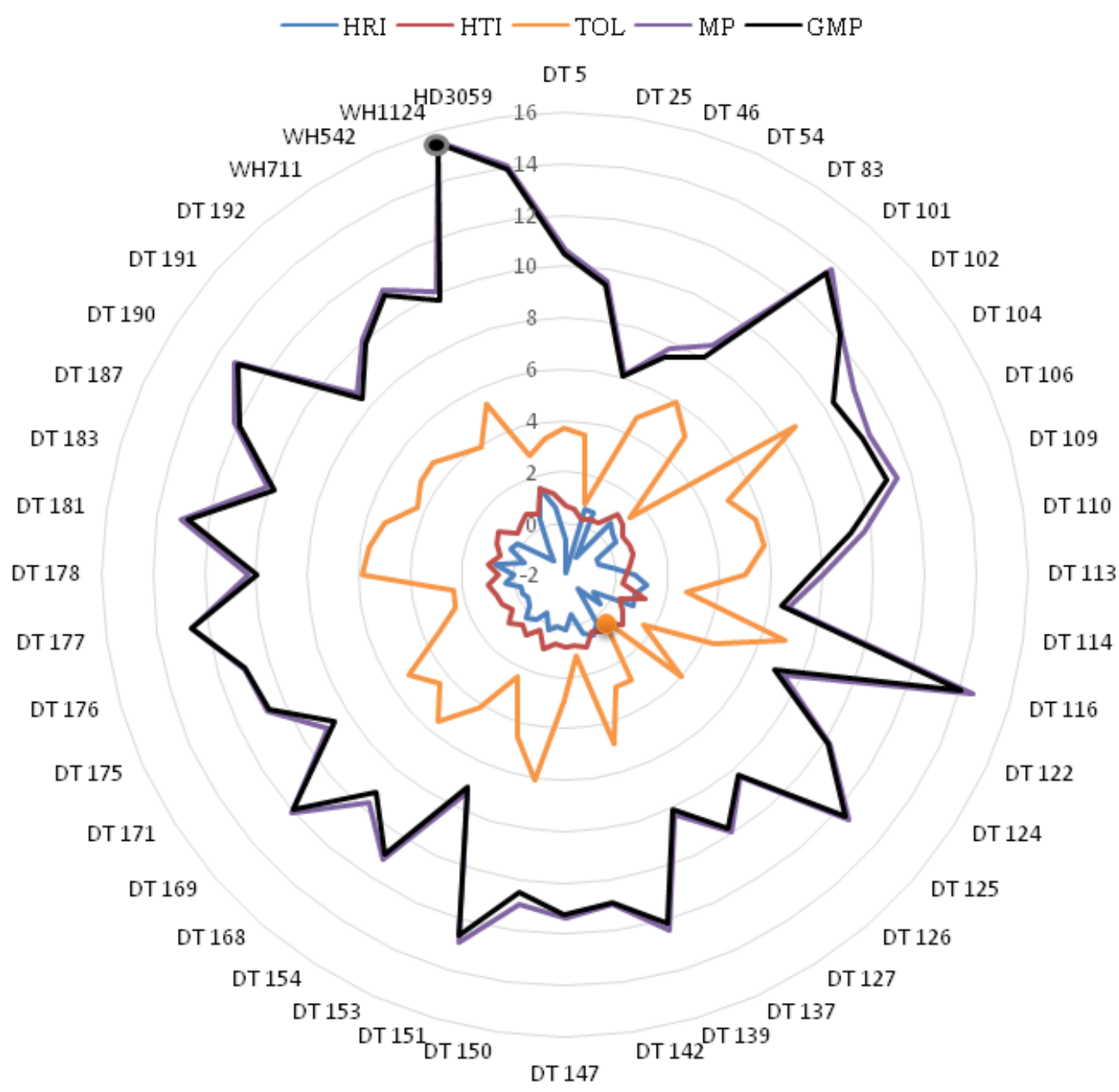

Fig. 1. Stress indices for grain yield in wheat accessions

Table 6. Rank of accessions based on different stress indices

\begin{tabular}{lllllllll}
\hline Accessions & & \multicolumn{3}{c}{ Individual Rank } & & Average rank & Overall rank \\
\hline & HSI & HRI & HTI & TOL & MP & GMP & & 22 \\
DT 5 & 20 & 38 & 22 & 17 & 24 & 23 & 24.00 & 22 \\
DT 25 & 22 & 44 & 31 & 16 & 33 & 31 & 29.50 & 34 \\
DT 46 & 4 & 7 & 44 & 2 & 44 & 44 & 24.17 & 23 \\
DT 54 & 39 & 10 & 40 & 27 & 40 & 40 & 32.67 & 39 \\
DT 83 & 43 & 41 & 37 & 41 & 36 & 38 & 39.33 & 44 \\
DT 101 & 23 & 8 & 4 & 32 & 4 & 4 & 12.50 & 5 \\
DT 102 & 3 & 13 & 10 & 4 & 11 & 10 & 8.50 & 4 \\
DT 104 & 44 & 16 & 22 & 44 & 15 & 24 & 27.50 & 28 \\
DT 106 & 29 & 35 & 20 & 30 & 20 & 20 & 25.67 & 27 \\
DT 109 & 31 & 36 & 15 & 38 & 14 & 15 & 24.83 & 25 \\
DT 110 & 39 & 27 & 32 & 39 & 31 & 32 & 33.33 & 41 \\
DT 113 & 42 & 6 & 39 & 31 & 39 & 39 & 32.67 & 39 \\
DT 114 & 25 & 2 & 43 & 9 & 43 & 43 & 27.50 & 28 \\
DT 116 & 30 & 4 & 2 & 43 & 2 & 2 & 13.83 & 7
\end{tabular}




\begin{tabular}{|c|c|c|c|c|c|c|c|c|}
\hline DT 122 & 39 & 3 & 42 & 23 & 41 & 42 & 31.67 & 38 \\
\hline DT 124 & 5 & 37 & 25 & 5 & 26 & 25 & 20.50 & 19 \\
\hline DT 125 & 13 & 30 & 9 & 19 & 9 & 9 & 14.83 & 11 \\
\hline DT 126 & 1 & 42 & 36 & 1 & 37 & 36 & 25.50 & 26 \\
\hline DT 127 & 11 & 19 & 28 & 11 & 30 & 28 & 21.17 & 21 \\
\hline DT 137 & 15 & 11 & 37 & 10 & 38 & 37 & 24.67 & 24 \\
\hline DT 139 & 26 & 12 & 10 & 29 & 10 & 11 & 16.33 & 14 \\
\hline DT 142 & 2 & 34 & 19 & 3 & 22 & 19 & 16.50 & 15 \\
\hline DT 147 & 10 & 22 & 14 & 13 & 15 & 14 & 14.67 & 9 \\
\hline DT 150 & 35 & 24 & 22 & 42 & 21 & 22 & 27.67 & 31 \\
\hline DT 151 & 16 & 19 & 8 & 25 & 7 & 8 & 13.83 & 7 \\
\hline DT 153 & 12 & 33 & 41 & 7 & 42 & 41 & 29.33 & 33 \\
\hline DT 154 & 23 & 23 & 17 & 20 & 17 & 17 & 19.50 & 17 \\
\hline DT 168 & 36 & 18 & 32 & 36 & 32 & 33 & 31.17 & 37 \\
\hline DT 169 & 21 & 26 & 12 & 24 & 12 & 12 & 17.83 & 16 \\
\hline DT 171 & 38 & 31 & 34 & 33 & 34 & 34 & 34.00 & 42 \\
\hline DT 175 & 13 & 28 & 20 & 14 & 23 & 21 & 19.83 & 18 \\
\hline DT 176 & 8 & 29 & 15 & 8 & 19 & 16 & 15.83 & 13 \\
\hline DT 177 & 6 & 14 & 7 & 6 & 8 & 7 & 8.00 & 3 \\
\hline DT 178 & 37 & 25 & 26 & 39 & 25 & 26 & 29.67 & 35 \\
\hline DT 181 & 28 & 5 & 6 & 37 & 6 & 6 & 14.67 & 9 \\
\hline DT 183 & 33 & 32 & 28 & 34 & 27 & 29 & 30.50 & 36 \\
\hline DT 187 & 16 & 17 & 13 & 22 & 12 & 13 & 15.50 & 12 \\
\hline DT 190 & 16 & 21 & 5 & 26 & 5 & 5 & 13.00 & 6 \\
\hline DT 191 & 34 & 40 & 35 & 28 & 35 & 35 & 34.50 & 43 \\
\hline DT 192 & 27 & 42 & 27 & 21 & 29 & 27 & 28.83 & 32 \\
\hline WH 711 (c) & 16 & 39 & 17 & 18 & 18 & 18 & 21.00 & 20 \\
\hline WH 542 (c) & 32 & 15 & 28 & 34 & 27 & 29 & 27.50 & 28 \\
\hline WH 1124 (c) & 7 & 1 & 1 & 12 & 1 & 1 & 3.83 & 1 \\
\hline HD 3059 (c) & 9 & 8 & 3 & 14 & 3 & 3 & 6.67 & 2 \\
\hline
\end{tabular}

Table 7. Correlation among different stress indices

\begin{tabular}{|c|c|c|c|c|c|c|c|c|}
\hline & Yp & Ys & HSI & HRI & HTI & TOL & MP & GMP \\
\hline Yp & 1.000 & & & & & & & \\
\hline Ys & $0.663^{* *}$ & 1.000 & & & & & & \\
\hline HSI & $0.228^{* *}$ & $-0.552^{* *}$ & 1.000 & & & & & \\
\hline HRI & 0.137 & 0.155 & -0.006 & 1.000 & & & & \\
\hline HTI & $0.872^{* *}$ & $0.931^{* *}$ & $-0.236^{* *}$ & $0.222^{*}$ & 1.000 & & & \\
\hline TOL & $0.560^{* *}$ & $-0.250^{* *}$ & $0.907^{* *}$ & 0.005 & 0.097 & 1.000 & & \\
\hline MP & $0.926^{* *}$ & $0.897^{* *}$ & -0.144 & 0.159 & $0.986^{* *}$ & $0.204^{*}$ & 1.000 & \\
\hline GMP & $0.889^{* *}$ & $0.931^{* *}$ & $-0.223^{*}$ & 0.159 & $0.992^{* *}$ & 0.119 & $0.996^{* *}$ & 1.000 \\
\hline
\end{tabular}

Yp, and Ys represent grain yield under normal and stress conditions, respectively 


\section{References}

1. Balla K, I Karsai, S Bencze and O Veisz. 2012. Germination ability and seedling vigour in the progeny of heat-stressed wheat plants. Acta Agronomica Hungarica 60(4): 299-308.

2. Bhusal N, AK Sarial, P Sharma and S Sareen. 2017. Mapping QTLs for grain yield components in wheat under heat stress. PLOS ONE 12(12): e0189594.

3. Bidinger F, V Mahalakshmi and G Rao. 1987. Assessment of drought resistance in pearl millet [Pennisetum americanum (L.) Leeke]. 1. Factors affecting yields under stress. Australian Journal of Agricultural Research 38(1): 37.

4. Caverzan A, A Casassola and SP Brammer. 2016. Antioxidant responses of wheat plants under stress. Genetics and Molecular Biology 39(1): 1-6.

5. Chapman SC, S Chakraborty, MF Dreccer and SC Howden. 2012. Plant adaptation to climate changeopportunities and priorities in breeding. Crop Pasture Science 63: 251-268.

6. Deryng D, D Conway, N Ramankutty, J Price and R Warren. 2014. Global crop yield response to extreme heat stress under multiple climate change futures. Environmental Research Letters 9(3): 034011.

7. Fan Y, C Ma, Z Huang, M Abid, S Jiang, T Dai, W Zhang, S Ma, D Jiang and X Han. 2018. Heat priming during early reproductive stages enhances thermotolerance to post-anthesis heat stress via improving photosynthesis and plant productivity in winter wheat (Triticum aestivum L.). Frontiers in Plant Science 9: 805.

8. Fernandez GC. 1993. Effective selection criteria for assessing plant stress tolerance. Adaptation of food crops to temperature and water stress 13: 181992257270 .

9. Fischer R and R Maurer. 1978. Drought resistance in spring wheat cultivars. 1. Grain yield responses. Australian Journal of Agricultural Research 29(5): 897.

10. Halford NG. 2009. New insights on the effects of heat stress on crops. Journal of Experimental Botany 60 (15): 4215-4216.
11. Hansen J, MK Sato and R Ruedy. 2012. Perception of climate change. Proceeding National Academy of Sciences 109:14726-14727.

12. Hassan MI, EA Mohamed, MA El-Rawy and KA Amein. 2016. Evaluating interspecific wheat hybrids based on heat and drought stress tolerance. Journal of Crop Science and Biotechnology 19(1): 85-98.

13. Hays D, E Mason, JH Do, M Menz and M Reynolds. 2007. Expression quantitative trait loci mapping heat tolerance during reproductive development in wheat (Triticum aestivum). In: Buck HT, JE Nisi and N Salomon (eds.), Wheat production in stressed environments. Developments in Plant Breeding, Springer, Amsterdam, 12: 373-382.

14. Hossain AB, RG Sears, TS Cox and GM Paulsen. 1990. Desiccation tolerance and its relationship to assimilate partitioning in winter wheat. Crop Science 30(3): 622-627.

15. ICAR-IIWBR. 2020. Director's Report of AICRP on Wheat and Barley 2019-20, Ed: G. P. Singh. ICAR-Indian Institute of Wheat and Barley Research, Karnal, Haryana, India. pp. 76.

16. Islam AU, AK Chhabra, SS Dhanda and $\mathrm{OH}$ Peerzada. 2017. Genetic diversity, heritability and correlation studies for yield and its components in bread wheat under heat stress conditions. IOSR Journal of Agriculture and Veterinary Science 10(05): 71-77.

17. Kaushal N, K Bhandari, KH Siddique and H Nayyar. 2016. Food crops face rising temperatures: An overview of responses, adaptive mechanisms, and approaches to improve heat tolerance. Cogent Food and Agriculture 2(1): 1134380.

18. Khan SU, JU Din, AQayyum, NE Jan and MA Jenks. 2014. Heat tolerance indicators in Pakistani wheat (Triticum aestivum L.) genotypes. Acta Botanica Croatica 74(1): 109-121.

19. Lobell DB and CB Field. 2007. Global scale climatecrop yield relationships and the impacts of recent warming. Environmental Research Letters 2(1): 014002. 
20. Mason RE, S Mondal, FW Beecher,A Pacheco, BJampala, AM Ibrahimand and DB Hays. 2010. QTL associated with heat susceptibility index in wheat (Triticum aestivum L.) under short-term reproductive stage heat stress. Euphytica 174(3): 423-436.

21. Meena VK, RK Sharma, PK Singh, N Kumar, N Jain, A Kumar and Ankita. 2019. Identification of terminal heat tolerance spring wheat genotypes using different selection indices for yield. International Journal of Chemical Studies 7(6): 1946-1952.

22. Mohammadi M, R Karimizadeh and M Abdipour. 2011. Evaluation of drought tolerance in bread wheat genotypes under dryland and supplemental irrigation conditions. Australian Journal of Crop Science 5(4): 487-493.

23. Mohammadi R and A Abdulahi. 2017. Evaluation of durum wheat genotypes based on drought tolerance indices under different levels of drought stress. Journal of Agricultural Sciences, Belgrade 62(1): 1-14.

24. Mohammadi-joo S, A Mirasi, R Saeidi-aboeshaghi, M Amiri. 2015. Evaluation of bread wheat (Triticum aestivum L.) genotypes based on resistance indices under field conditions. International Journal of Biosciences 6(2): 331-337.

25. Munjal R and SS Dhanda. 2016. Assessment of drought resistance in Indian wheat cultivars for morpho-physiological traits. Ekin Journal of Crop Breeding and Genetics 2(1): 74-81.

26. Ortiz R, KD Sayre, B Govaerts, R Gupta, G Subbarao, T Ban, DHodson, JM Dixon, J Ivan Ortiz-Monasterio and M Reynolds. 2008. Climate change: Can wheat beat the heat? Agriculture, Ecosystems and Environment 126(1-2): 46-58.

27. Paliwal R, MS Roder, U Kumar, JP Srivastava and AK Joshi. 2012. QTL mapping of terminal heat tolerance in hexaploid wheat (Triticum aestivum L.). Theoretical and Applied Genetics 125(3): 561-575.

28. Puri RR, NR Gautam and AK Joshi. 2015. Exploring stress tolerance indices to identify terminal heat tolerance in spring wheat in Nepal. Journal of Wheat Research 7(1): 13-17.

29. Rosielle AA and J Hamblin. 1981. Theoretical aspects of selection for yield in stress and non stress environment. Crop Science 21(6): 943-946.

30. Sareen S, N Bhusal, M Kumar, PK Bhati, R Munjal, J Kumari, S Kumar and AK Sarial. 2020. Molecular genetic diversity analysis for heat tolerance of indigenous and exotic wheat genotypes. Journal of Plant Biochemistry and Biotechnology 29(1): 15-23.

31. Sharma A, RS Rawat, JS Verma and JP Jaiswal. 2013. Correlation and heat susceptibility index analysis for terminal heat tolerance in bread wheat. Journal of Central European Agriculture 14: 57-66.

32. Sharma D, R Singh, J Rane, VK Gupta, HM Mamrutha and R Tiwari. 2016. Mapping quantitative trait loci associated with grain filling duration and grain number under terminal heat stress in bread wheat (Triticum aestivum L.). Plant Breeding 135(5): 538-545.

33. Sharma L, M Priya, N Kaushal, K Bhandhari, S Chaudhary, OP Dhankher, PV Prasad, KH Siddique and H Nayyar. 2019. Plant growth-regulating molecules as thermoprotectants: Functional relevance and prospects for improving heat tolerance in food crops. Journal of Experimental Botany 71(2): 569-594.

34. Suresh, OP Bishnoi and RK Behl. 2018. Use of heat susceptibility index and heat response index as a measure of heat tolerance in wheat and triticale. Ekin Journal of Crop Breeding and Genetics 4(2): 39-44. 